\title{
Altering comprehension: The effect of biasing titles on text comprehension
}

\author{
ELY KOZMINSKY \\ University of Colorado, Boulder, Colorado 80309
}

\begin{abstract}
Titles can alter the comprehension of a text by affecting the selection of information from a text and the organization of this information in memory. Text comprehension is assumed to involve an organizational process that results in the formation of a text base, an ordered list of semantic units-propositions. The text base can be used as a retrieval scheme to reconstruct the text. Procedures for assigning propositions as more relevant to some themes as compared to other themes are developed and applied to texts. Texts with biasing titles were used in an experiment to demonstrate that immediate free recall is biased toward the theme emphasized in the title. The comprehension process which is guided by the text's thematical information is described.
\end{abstract}

The process of comprehending a text involves the reduction of the information presented in the text. Three interactive factors participate in this process: the reader's goals, the application of previous organized experience, and contextual information in the discourse. This paper concentrates on the effect of one type of superordinate contextual information: the title given to a text.

In order to describe the role of a title in text comprehension, a theory of text analysis (Kintsch, 1974) is employed here. This theory is elaborated, so that it becomes possible to decide for a given text which semantic elements in it are relevant to each of several titles that may be assigned to the text.

It is not the aim of this paper to compare the adequacy of different theoretical approaches to text analysis. Theories (e.g., Frederiksen, 1975; Kintsch, 1974; Meyer, 1975; Crothers, Note 1) vary in their fineness of the analysis applied to texts and in their emphasis on different aspects of texts. Although it is possible to embed parts of the following exposition in other theories, several concepts that are unique to Kintsch's (1974) approach offer a more suitable setting for the subject raised in this work.

The literature on contextual information is usually discussed under specific subjects such as advance organizers (Frase, 1975) and adjunct questions (Anderson \& Biddle, 1975). Titles are usually considered one kind of advance organizer. Meyer (1975) associates titles with a type of signaling information in the discourse that "prematurely reveals information

This research was partially supported by Grant 15872 from the National Institute of Mental Health to Walter Kintsch. I wish to thank Walter Kintsch and Douglas Vipond for their comments on this paper and Paul Hughes for assistance in constructing the materials for the experiment. Send reprint requests to the author at the Department of Psychology, University of Colorado, Boulder, Colorado 80309. abstracted from the content occurring later in the text." As advance organizers, titles facilitate the assembly of previous knowledge that will incorporate the "new" textual information (Ausubel, 1968). They serve as pointers, as assumed, "given" information that makes contact with previous knowledge in memory. If no previous knowledge is available, titles serve as an anchor point in memory around which the incoming textual material will be organized. This description is congruent with the distinction between "given" and "new" information in sentences which was made by Haviland and Clark (1974) and Clark (Note 2). Thus titles, or advance organizers in general, may facilitate comprehension.

Research on the use of titles usually shows that knowledge of the title prior to exposure to the text increases recall compared to a no-title condition (Bransford \& Johnson, 1972; Dooling \& Lachman, 1971). Presenting the title after exposure to the text does not facilitate recall (Bransford \& Johnson, 1972; Dooling \& Mullet, 1973; Frase, 1969), suggesting that the locus of the effect is in acquisition. But the material that was used in these experiments was difficult and almost incomprehensible without a proper title, leaving open the possibility that titles may also play a role as a retrieval scheme, as suggested by Gagné (1969) and Gagné and Wiegand (1970).

If a title assumes the role of an anchoring point or superordinate context around which the text is organized, then biasing titles may alter the comprehension of the text. They may provide different interpretations to context elements in the text, or alternative organizations of the ideas in the text. Ideas that were central for one title may be less important when another title is used, and information that does not fit a biased organization of the text may be overlooked, as was shown by Schallert (1976).

Schallert (1976) used two-way ambiguous paragraphs that could be disambiguated with a proper context 
(title). Each paragraph had two themes. Some of the words in the paragraph could be interpreted according to one theme or the other. One meaning was determined to be the "strong" meaning and one the "weak" meaning, according to subjects' judgments. Recognition scores for features in the paragraphs that were consonant with the strong or the weak meaning were obtained on several tasks. Schallert's results suggest that the semantic organization according to one context biased the recognition responses toward that context compared to responses consonant with the second context $(45 \%$ vs. $26 \%$ ). On the other hand, the overall proportion of recognition responses that were either consonant or dissonant with the biasing context did not vary as a function of the context presented (73\% for the strong context and $70 \%$ for the weak one). Apparently, biasing contexts did not affect the overall acquisition from a text, but controlled the selection of information from the text.

A similar pattern of results was obtained by Frase and Kreitzberg (1975). Subjects read a biographical passage and were instructed to learn (positive) or not to learn (negative) information that was related either to a given list of topics, or to sentences that began with some given words. Reading time was fixed for all subjects, and after an hour of unrelated activity, the subjects were given an answer completion test. Significant facilitation of performance was obtained for the "word" condition for positive instructions and inhibition for the negative instructions. No significance, but a similar pattern, was found for the "topic" condition.

The similarity of these two studies lies in the selectional process that they initiated. However, they differed in the form of context used, the selectional targets, and the performance measures. In Schallert's (1976) experiment, the selectional target was a word meaning, while in Frase and Kreitzberg's (1975) study, it was a sentence relevant to a presented topic. The processing of irrelevant sentences is more complex than selecting a meaning for a single word, since in order to determine the relevance of a sentence to a topic, its semantic content must be extracted and compared to a topic list.

Frase and Kreitzberg's failure to obtain a stronger effect for the "topic" condition in comparison to the "word" condition can also be explained by the posttest that was used. The completion task used in their experiment may have reduced the effect of the "topic" condition by providing contextual information that was sufficient to retrieve even weakly encoded information in the sentences that were irrelevant to the topic list. If a more context-free task were employed, such as free recall, a stronger effect might have been obtained.

The present experiment demonstrates alterations in text comprehension as a function of varying contextual information in the form of biasing titles. The task used is immediate free recall. In order to score the recall protocols and assign elements in the text as more or less relevant to a biasing title, a model of the semantic organization of information in the text developed by Kintsch (1974) is used. The model will be briefly presented below: along with a method for extracting information from a text that is relevant to one of several possible themes in it.

The sources of change in text comprehension are assumed to be mainly of two types: a selection process, which causes some elements in a text that are less relevant to a biasing title to be less processed and subsequently less recalled; and an organizational process, which assigns elements in the text that are more remotely related to the topic of the text (the biasing title) a less central place in the perceived semantic structure of the text. These less central elements are less retrievable and, therefore, recalled less.

\section{Texts' Analysis}

A text base is assumed to reflect the semantic organization of a text. It consists of a structured list of propositions. A proposition can be thought of as the basic idea unit of the text. It is defined, recursively, as an "n-tuple" which consists of a relation and $\mathrm{n}-1$ arguments. Each argument fulfills a unique semantic role. An argument can be either a word-concept, which is an abstract entity expressed as a word in the text, or a proposition. This definition is derived from Fillmore's (1968) case grammar. In Table 1, a set of sentences is analyzed into their underlying propositions. The first proposition consists of a relation (in this case a verb), PLAN; the argument DEBBIE has the semantic role of agent, in the role of the object there is another proposition (Proposition 2); the semantic role of the goal is BETTY. The semantic cases that may appear in a proposition are: Agent, Experiencer, Instrument, Object, Source, and Goal (see Kintsch, 1974).

Propositions are connected to each other and form a semantic network by means of a repetition rule: Two propositions are connected in the text base if they have an argument in common or if one proposition is an argument of the second proposition. The propositional analysis of a text produces a text base which is connected; that is, there exists a path between any two propositions in the text base.

In addition to the connectivity property, the propositions in the text base are partially ordered according to a subordination relation, and thus form a hierarchical structure. The starting points in the structure (one or more superordinate propositions) are determined according to the theme(s) or subject matter of the text. In Table 1-d two such propositional structures are displayed according to the two biasing titles. The assignment of more than one structural interpretations to a text is denoted as structural ambiguity. Both structural interpretations are included in the text base if they cannot be resolved through 
Table 1

Partial Text Base for an Episode from the Narrative Text
(a)
(T1) Betty's Weight Problem
(T2) My (Debbie's) Nursing Assignment
(1) (POSSESS, BETTY, 2)
(2) (WEIGHT, PROBLEM)
(1) (POSSESS, DEBBIE, 2)
(2) (NURSING, ASSIGNMENT)

(b) Text: I (Debbie) also planned an exercise program for her (Betty). At first, she (Betty) was most resistant to this change. I (Debbie) made it a point to exercise with her. Later, she (Betty) would exercise without coaxing.

(d) Levels Assignment

$\begin{array}{cc}\text { T1 } & \text { T2 } \\ 2 & 1 \\ 3 & 2 \\ 3 & 2 \\ 1 & 2 \\ 2 & 3 \\ 2 & 3 \\ 2 & 3 \\ 3 & 2 \\ 2 & 3 \\ 2 & 2 \\ 3 & 2 \\ 2 & 3 \\ 3 & 3 \\ 3 & 3 \\ 2 & 3\end{array}$

(c) Propositional Analysis

(1) (PLAN,DEBBIE, 2,BETTY)

(2) (EXERCISE,PROGRAM)

(3) (ALSO, 1)

(4) (RESIST,BETTY,CHANGE)

(5) (REFERENCE,CHANGE,2)

(6) (EXTENT OF,4,MOST)

(7) (TIME OF:AT FIRST,4)

(8) (MAKE POINT,DEBBIE,9)

(9) (CONJUNCTION:WITH,10,11)

(10) (EXERCISE,BETTY)

(11) (EXERCISE,DEBBIE)

(12) [CONSEQUENCE:BECAUSE,4,8] *

(13) (MANNER:WITHOUT,10,COAXING)

(14) (TIME:LATER,10)

(15) [CONTRAST:AT FIRST_LATER_4,10]* (e) Relevance Assignment Theme Rule

$\begin{array}{ll}\text { T2 } & 2 \\ \text { T2 } & 3 \\ \text { T2 } & 1 \\ \text { T1 } & 1 \\ \text { T1 } & 3 \\ \text { T1 } & 1 \\ \text { T1 } & 1 \\ \text { T2 } & 2 \\ \text { T2 } & 3 \\ \text { T1 } & 1 \\ \text { T2 } & 1 \\ \text { T2 } & 2 \\ \text { T1 } & 1 \\ \text { T1 } & 1 \\ \text { T1 } & 1\end{array}$

Note-(a) Titles and their propositional analysis. (b) Text (for clarity, proper names are added in parentheses). (c) Propositional analysis of the text. (d) Levels assignment to the propositions in $1 \mathrm{c}$ from point of view of the two themes given by the titles in la. (e) Relevance assignment of the propositions in $1 c$ to the themes in Ia and the rules used (see text). *Implied proposition

the information in the text. When a title is assigned to a text, it is assumed that the title carries the thematic information in the text. This thematic information is assumed to occupy the highest level in the text base. Therefore, the title propositions are the most superordinate ones in the text base.

A text base can be extended to include propositions that are implied in a text but are not directly represented in its surface form. Propositions 12 and 15 in Table 1 are examples. A text base that includes elaborative information is called the explicit text base. The implicit text base consists only of propositions that are derived directly from the text and implied propositions that are required to insure the connectivity of the text base. Propositions 12 and 15 are therefore not included in the implicit text base. The decision when to use an implicit or explicit text base depends on the experimental task in question. In this case, where the subjects' task is to recall the text, only minimal elaborative processing of the text is assumed on the part of the subjects. Therefore, the implicit text base is a sufficient representation. In cases where subjects are expected to answer questions that involve inferences from the texts (e.g., Thorndyke, 1976), an explicit text base is a more suitable representation. In the following discussion the term text base refers to an implicit text base. (For a more detailed description of the construction and use of propositional text bases, see Turner \& Greene, Note 3).

\section{Theme-Relevant Propositions}

A proposition or an episode can be assigned as relevant to one or more themes, or to neither one of them, according to the biasing titles that are congruent with each detectable theme. This is achieved by pattern matching the propositions of the text base to the propositions that underlie the thematic information in the text.

At the level of a single proposition, the following three rules are applied to determine whether a proposition is more relevant to one theme or another. (The first rule is a special case of the second, and it is introduced to simplify the explanation.) Rule 1: If a proposition contains at least one argument that also appears in a theme-proposition (as given by the appropriate title) and does not appear in a different theme-proposition, then this proposition is relevant to the first theme. There are two cases of this rule. First, if all the arguments of the proposition are wordconcepts, Rule 1 can be directly applied. For example, Proposition 4 in Table 1 has an argument, BETTY, which also appears in the title, "Betty's Weight Problem." No argument in that proposition is contained in the propositions of the second biasing title, "My (Debbie's) Nursing Assignment." Therefore, Proposition 4 is relevant to the theme "Betty's Weight Problem." The second case arises when some of the arguments of the to-be-matched proposition are themselves propositions. Rule 1 can then be applied 
only after the relevance of these propositions is established. For example, Proposition 13 in Table 1 has one argument which is a proposition (i.e., 10). If Proposition 10 is relevant to one theme, then Proposition 13 is also relevant to that theme. By applying Rule 1, Proposition 10 is assigned to the theme, "Betty's Weight Problem." Thus, Proposition 13 is also relevant to this theme.

The second rule deals with the case in which a proposition contains arguments that are contained in more than one theme's propositions. Rule 2: If a proposition has arguments that match arguments in different themepropositions, then the relevance of the proposition to a theme is decided according to the matching argument in the proposition which: (a) matches an argument of a more superordinate theme-proposition, or (b) occupies the most prior case. Rule $2 \mathbf{a}$ has priority over Rule $2 \mathbf{b}$. The priority order of the semantic cases from high to low is: agent, experiencer, instrument, object, source, and goal. Again, there are two cases as in Rule 1, and they are handled in a similar way. As an example for Rule 2, consider Proposition 1 in Table 1, which has arguments that match arguments in both themepropositions. Since the agent case contains the argument DEBBIE, which matches the same argument in "My (Debbie's) Nursing Assignment," the whole proposition is relevant to this theme.

The third rule applies when the first two fail. In that case no argument in the proposition matches arguments of any one of the theme-propositions. Rule 3: Determine the relevance of a proposition according to the relevance of its immediate superordinate proposition in the text base. For example, the relevance of Proposition 2 in Table 1 is decided by Rule 3.

The order of rule application is from 1 to 3 . First, Rule 1 is attempted until no more decisions can be made using this rule. Then Rule 2 is applied; Rule 1 is tried again followed by Rule 2; only then is Rule 3 attempted, and finally the scan starts all over again from Rule 1. Table 1 shows the relevance of each proposition to a theme, and the rule which was used in determining it.

It is important to comment at this point that the rules described above are based entirely on the semantic organization of propositions as expressed by the text base. No information from the text's surface is considered. If surface information is used, thematicity can be determined by the positioning of arguments in the surface (Halliday \& Hasan, 1976). For example, the sentence, "Debbie planned an exercise program for Betty," has as its theme the argument DEBBIE. On the other hand, the sentence, "Betty had an exercise program planned for her by Debbie," has as its theme BETTY. Surface information is crucial in extracting thematic information in phrases and eventually can affect the extraction of thematic information from a text when no theme is given in advance. When thematic information is given about the text (as in this case in the form of a title), the given theme-propositions are assumed to be domiriant in assigning relevance of propositions over their surface appearance.

When the hierarchical structure of a partial text base does not change as a function of the theme (title) used, the assignment procedure of theme-relevant propositions can be considerably simplified. In such a partial text base, the levels differences of any two propositions does not vary as a function of the applied theme-propositions. In other words, either all the propositions in this partial base change levels in the hierarchy, or none at all. In that case, the most superordinate proposition in the partial text base that matches the theme-propositions via application of Rule 1 , or Rule 2, determines the relevance assignment of all its subordinate propositions via the application of Rule 3 .

In the experiment reported here, theme-relevant propositions were established according to the procedure outlined above. Note, however, in Table 1 the simplified procedure was not applied, since the level changes were not constant. Compare, for example, level changes of Propositions 1 and 4 as a function of the two themes used.

\section{Main and Secondary Themes}

For each title it is possible to decide whether it reflects a more or less dominant theme in the text. Several criteria can be employed for this purpose.

Structural criterion. When detection of single propositions, or of entire episodes that are related to one theme, does not affect the connectivity of the text base, this theme is a secondary one. This criterion can be applied to the narrative text shown in the Appendix. Compare the two short summaries that can be produced as a function of emphasizing each theme through its appropriate title:

\section{Betty's Weight Problem}

Betty, an obese woman, gained weight while dieting. When forced to stay on her diet, to exercise, and to do a chore, she lost weight and channelled her energy constructively.

\section{My (Debbie's) Nursing Assignment}

Debbie had a successful nursing assignment. Her patient was an obese woman, who gained weight while dieting. When Debbie forced her to stay on her diet, exercise, and do a chore, she lost weight and channelled her energy constructively.

The first summary does not mention anything about the nursing assignment. That theme is completely deleted without any effect on the other theme. In the second summary, some information from the weightproblem theme must be maintained in order to insure the coherence of this summary. Thus, the main theme is "Betty's Weight Problem," and the secondary theme is "My Nursing Assignment." 
Quantitative criterion. When the structural criterion is not effective (i.e., deletion of propositions or episodes that are relevant to one title does not affect the acceptability of the remaining text), the size of the respective theme-relevant proposition sets can be used to determine the dominance of a theme. The larger the number, the more dominant the theme. The descriptive text may be analyzed by this criterion, since deletion of episodes that are relevant to "Sights of the City" would not affect the acceptability of the episodes that are relevant to "Sounds of the City."

Additional criteria. When the removal of themerelevant propositions of either theme will affect the acceptability of the other theme, additional criteria may be used in determining which theme is dominant; for instance, position in the text of information which is relevant to one theme, or references of one themerelevant proposition set to other sets in the text. Although the report-type text (see Appendix) has some elements in it that indicate the presence of intermixed thematic information, the structural criterion can still be applied. Removal of the Coast Guard propositions does not affect the description of the smugglers' activities. Furthermore, "The Smugglers" is an appropriate title for the first passage in that text. Therefore, "The Smugglers" was considered as the title that reflects a more dominant theme than "The Coast Guard."

\section{METHOD}

\section{Subjects}

The subjects were 45 University of Colorado students who participated in the experiment in fulfillment of a course requirement.

\section{Material}

Three texts, each about 300 words long, were constructed. The three texts differed from each other in context and structure: They may be classified as descriptive, report, and narrative. The texts are given in the Appendix. Three titles were constructed for each text. Two of the titles were biasing titles and the third one was a concatenation of the first two (a "combined" title). The list of titles is given in Table 2, together with summary information about the texts: number of words, number of propositions, and number of propositions and words that are relevant to each theme according to the assigned titles.

\section{Procedure}

Each subject was asked to read and recall the three texts. A subject sat in front of a four-phase 70 CRT terminal which was driven by a Sigma 3 computer. The subject was told that he would receive a short text, about one page long, to read and recall. He was asked to try to comprehend the text. The title of the text was printed on the top of it. Reading time was recorded by having the subject press a button on the terminal. When the subject finished reading, he put the text aside and recalled as much of the text as he could by typing it to the terminal screen. Verbatim recall was not encouraged.

\section{Design}

The experimental design was a 3 by 3 by 3 by 2 partial factorial. The independent variables were presentation order, texts, titles (main, secondary, and combined), and themerelevant propositions (main theme and secondary theme). The first three variables were combined in a Latin square; the fourth variable was factorially combined with the first three. The dependent variables were reading time and proportion of propositions recalled. For reading time, the fourth independent variable is not applicable.

\section{Scoring}

Each recall protocol was scored against its appropriate text base. A detailed discussion of the scoring procedure is given in Kintsch, Kozminsky, Streby, McKoon, and Keenan (1975) and in Turner and Greene (Note 3). Generally, the text base served as a template against which the recall protocols were matched. Similar scoring procedures have been found reliable in several previous studies (Kintsch et al., 1975; Meyer, 1975).

\section{RESULTS}

\section{Recall}

The main interaction between titles and themerelevant propositions was significant $[F(2,72)=5.92$, $\mathrm{p}<.005]$. The proportion recall of propositions that were relevant to a theme consonant with a presented

Table 2

Titles (Main-M, Secondary-S, Combined-C) for Each Text Type and Number of Words, Propositions in a Text, and Propositions Relevant to a Title

\begin{tabular}{|c|c|c|c|c|}
\hline \multirow[b]{2}{*}{ Title } & \multicolumn{2}{|c|}{ Number of Words Per } & \multicolumn{2}{|c|}{ Number of Propositions Per } \\
\hline & Text & Title & Text & Title \\
\hline $\begin{array}{l}\text { Descriptive Text } \\
\text { M: The Sights of the City } \\
\text { S: The Sounds of the City } \\
\text { C: The Sights and Sounds of the City }\end{array}$ & 313 & $\begin{array}{l}174 \\
139\end{array}$ & 149 & $\begin{array}{l}79 \\
70\end{array}$ \\
\hline $\begin{array}{l}\text { Report Text } \\
\text { M: The Smugglers } \\
\text { S: The Coast Guard } \\
\text { C: The Coast Guard and the Smugglers }\end{array}$ & 276 & $\begin{array}{l}142 \\
134\end{array}$ & 114 & $\begin{array}{l}55 \\
59\end{array}$ \\
\hline $\begin{array}{l}\text { Narrative Text } \\
\text { M: Betty's Weight Problem } \\
\text { S: My Nursing Assignment } \\
\text { C: My Nursing Assignment/Betty's Weight Problem }\end{array}$ & 295 & $\begin{array}{l}162 \\
133\end{array}$ & 128 & $\begin{array}{l}71 \\
57\end{array}$ \\
\hline
\end{tabular}


Table 3

Percentage Propositional Recall as a Function of Text Type (Descriptive, Report, and Narrative), Titles, and Theme-Relevant Propositions (Main and Secondary Themes)

\begin{tabular}{|c|c|c|c|c|c|c|c|c|c|}
\hline \multirow[b]{2}{*}{ Title } & \multicolumn{4}{|c|}{$\begin{array}{c}\text { Main Theme-Relevant Propositions } \\
\text { Text }\end{array}$} & \multicolumn{4}{|c|}{$\begin{array}{c}\text { Secondary Theme-Relevant Propositions } \\
\text { Text }\end{array}$} & \multirow{2}{*}{$\begin{array}{l}\text { Tota } \\
\text { Mean }\end{array}$} \\
\hline & Descriptive & Report & Narrative & Mean & Descriptive & Report & Narrative & Mean & \\
\hline $\begin{array}{l}\text { Main } \\
\text { Secondary } \\
\text { Combined }\end{array}$ & $\begin{array}{l}20.3 \\
18.1 \\
21.6\end{array}$ & $\begin{array}{l}27.5 \\
31.3 \\
23.0\end{array}$ & $\begin{array}{l}40.9 \\
32.4 \\
35.9\end{array}$ & $\begin{array}{l}29.6 \\
27.2 \\
26.8\end{array}$ & $\begin{array}{l}13.9 \\
20.5 \\
22.4\end{array}$ & $\begin{array}{l}22.0 \\
29.9 \\
22.9\end{array}$ & $\begin{array}{l}33.5 \\
29.8 \\
38.7\end{array}$ & $\begin{array}{l}23.1 \\
26.7 \\
28.2\end{array}$ & $\begin{array}{l}26.3 \\
27.0 \\
27.5\end{array}$ \\
\hline Mean & 20.0 & 27.2 & 36.4 & 27.9 & 19.1 & 24.9 & 34.0 & 26.0 & \\
\hline
\end{tabular}

title was $28.2 \%$ vs. $25.2 \%$ for a theme dissonant to a presented title. The main source of this interaction was a reduction in recall of the secondary theme-relevant propositions for the main title presented, in comparison to recall when the secondary title was presented. Order of texts was highly significant $[F(2,72)=10.94$, $\mathrm{p}<.001]$. Recall increased from $23.5 \%$ for the text presented first to $28.1 \%$ and $29.2 \%$ for the second and third presentations, respectively, reflecting a practice effect. Order did not interact with any of the other variables. As can be expected, the three texts differed in recall. The proportion recall for the narrative, report, and descriptive texts was $35.2 \%, 26.1 \%$, and $19.1 \%$, respectively $[F(2,72)=75.22, p<.001]$. The recall results, collapsed over order, are shown in Table 3. Although the interaction of titles and theme-relevant propositions was significant, the effect of titles on overall recall was not (see Table 3). Main theme-relevant propositions were recalled slightly better than secondary theme-relevant propositions $(27.9 \%$ vs. $26.0 \%$ ), but not significantly so.

\section{Reading Time}

Analyzing reading time as a function of number of propositions in the text base revealed only two effects. Reading time per proposition decreased from the first to the third presentation $[1.250,1.145$, and $1.062 \mathrm{sec}$ per proposition in the text base, $F(2,72)=4.65$, $\mathrm{p}<.05]$. The second significant effect was the text variable. Reading times were $1.020,1.405$, and $1.032 \mathrm{sec}$ per proposition in the text base for the descriptive, report, and narrative texts, respectively $[F(2,72)=25.01, p<.001]$. Apparently, subjects spent more time on the report. No differences were detected among titles, with reading times of $1.121,1.140$, and $1.197 \mathrm{sec}$ per proposition for the main, secondary, and combined titles $(\mathrm{F}<1)$.

When analyses of reading time as a function of number of propositions recalled were performed, these two effects were maintained. Subjects spent 7.065 , 4.658 , and $4.251 \mathrm{sec}$ per proposition recalled for the first, second, and third text they read $[F(2,72)=15.96$, $\mathrm{p}<.001]$. Reading time was $5.979,6.909$, and $3.089 \mathrm{sec}$ per proposition recalled for the descriptive, report, and narrative texts $[\mathrm{F}(2,72)=51.04, \mathrm{p}<.001]$.
Again, no difference in reading time per proposition recalled was detected among titles. The results were $5.351,4.949$, and $5.675 \mathrm{sec}$ per proposition for the main, secondary, and combined titles, respectively.

\section{Levels Analysis}

Another feature of the analysis that was obtained is the levels effect. Recall of propositions decreased with their decreased position in the text base hierarchy. This effect is well established for text material (Kintsch et al., 1975; Meyer, 1975). Table 1 gives an example of levels assignment for each theme for an episode in the narrative text. As can be seen, each theme produces a different level organization. We can predict, then, that plotting propositional recall given a theme as a function of its appropriate levels organization will produce the levels effect. On the other hand, plotting the same propositional recall against the level organization appropriate to the second theme (inappropriate structure) will reduce this effect. This analysis is, of course, feasible only if enough propositions change level when a title changes. This was the case only for the narrative text. In Figure 1 the relevant recall results are shown for this text. Part $\mathbf{A}$ of the figure displays a typical levels effect. In Part B the recall of only those propositions that changed level as a function of the title (15\% of the propositions in the text) is given. When the recall of the appropriate level organization is compared with the inappropriate organization, it can be seen that the levels effect was reduced by the inappropriate organization $\left[\chi^{2}(2)=7.045, \mathrm{p}<.05\right]$.

\section{DISCUSSION}

Text comprehension is in part a selection process which is guided by advance information about the text in the form of title. This conclusion is suggested by both the differential recall of theme-relevant propositions and the lack of difference in overall recall and reading times of the texts as a function of the biasing titles.

This selection process is itself part of the process of extracting a text base from a text during comprehension. The theoretical text base is assumed to be an ideal text base. That is, in its construction no memory limitations were assumed, and no information outside 


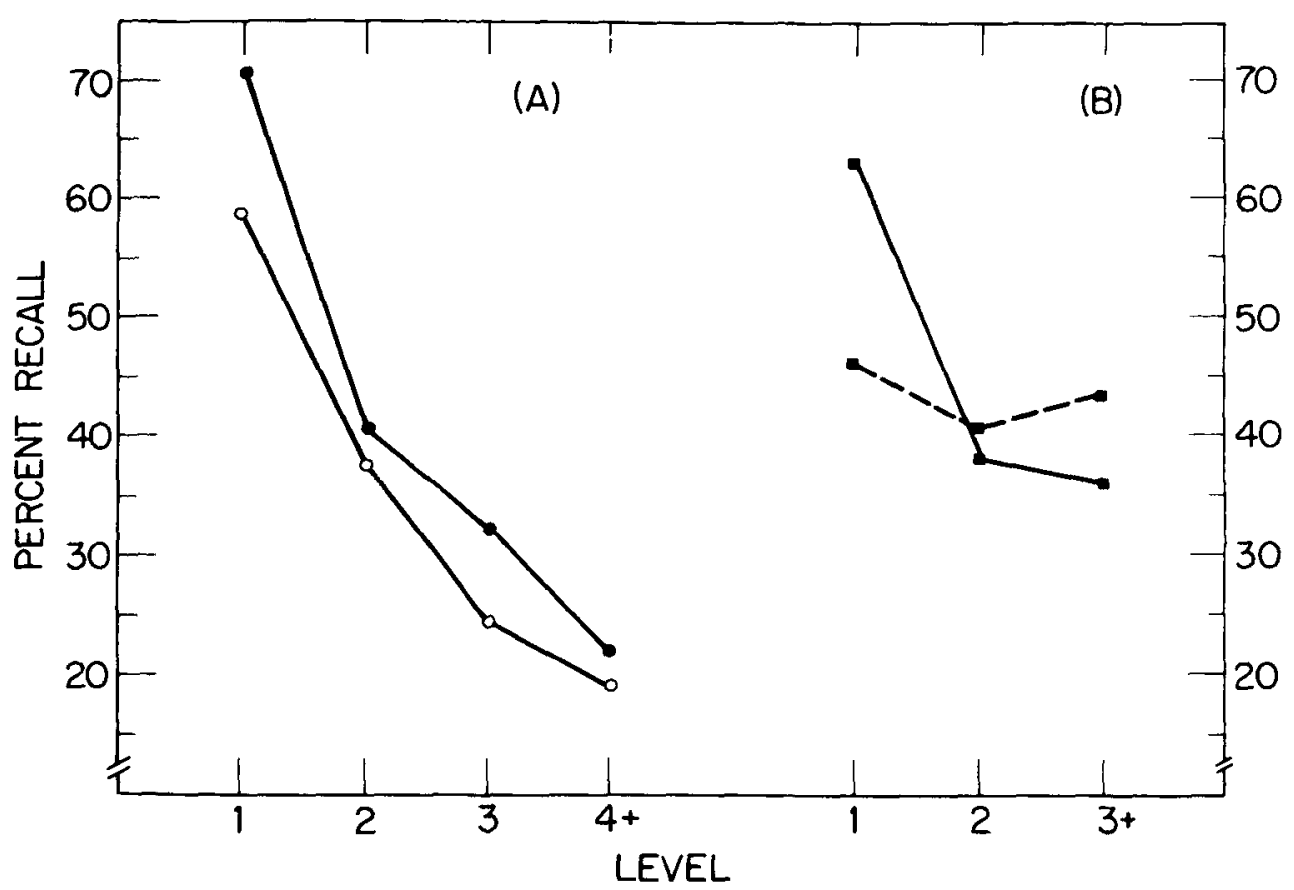

Figure 1. Proportion recall of propositions as a function of their level in the text base of the narrative text. (A) For the text base as a whole given the main (filled circles) or the secondary title (unfilled circles). (B) For propositions that change levels in the text base as a function of the title presented. The unbroken line shows recall as a function of the level according to the appropriate text base hierarchy, the broken line according to the inappropriate text base hierarchy.

the text itself was used unless such information was necessary to render the text base connected. It is suggested that when the reader tries to comprehend a text he is engaged in a similar text base construction. The reader's text base differs in two respects from the theoretical one. First, the reader's text base is incomplete. Not all propositions and their connections in the theoretical text base are in the reader's base because of comprehension failures due to memory limitations. Second, the reader's text base is supplemented by additional propositions from his general knowledge, in order to adjust for comprehension failures or to elaborate the text base according to the task requirements.

The reader, upon encountering a text, extracts from it (following perceptual operations, word identification, and a partial syntactic analysis) semantic units in the form of propositions. These propositions are stored in memory in the context of previously extracted propositions from a text and general knowledge currently active in memory. (A proposition is active in memory if it is a newly extracted one from a text, or if it is a proposition that was previously matched successfully with incoming propositions, or if it is held active by a rehearsal process.) The storage of a proposition is completed by a pattern-matching process between the newly extracted proposition and the other active propositions in memory. Upon a successful match of the incoming proposition, it is connected to those matched propositions. Eventually, this process leads to the formation of a connected set of propositions in memory.

During this process some propositions are assigned the role of superordinate propositions, together with propositions that are generated from information already in memory. This assignment is accomplished via macroprocesses that extract thematic information to establish the macrostructure of the proposition set. This process is discussed in detail in Kintsch (in press) and van Dijk (1976). The resulting macrostructure may later serve as a retrieval scheme from which the text can be reconstructed.

Superordinate propositions are held active in memory more frequently than other propositions. This is because of their assumed role in the text base that results in more frequent rehearsal, since they are more frequently matched with newly incoming propositions. As suggested before, the title propositions are such superordinate propositions. Therefore, they are rehearsed more often and serve as a nucleus that connects propositions that successfully match the title or other propositions that were connected to this title before. The result is a "growing" text base which is biased in the direction of the title propositions, just as a growing crystal can be biased by an initial contamination.

If a proposition is extracted from the text and does not successfully match the title propositions or other 
active ones, it may not be connected to the text base. If the unconnected proposition is needed later as a superordinate for additional incoming propositions, the whole set of propositions may not be connected to the main text base. In that case, if the main text base is used as a retrieval scheme for a later reconstruction of the text, the probability of recalling the unconnected set may be reduced. This is what was denoted before as the selection process. It is actually a failure to connect part of the information in the text to the main extracted text base. In that case, if a generalized title is introduced, it is expected that the resulting text base will be connected and recall may be enhanced. We suggest that this is what happened with the combined title for the descriptive text in this experiment. This explanation is consistent with Meyer's (1975) findings that selection affects higher levels in the text base, while retrieval considerations affect lower levels.

The biasing title propositions that serve as a nucleus for the formation of the text base may interfere with the extraction of other thematical information that was otherwise assigned a superordinate role in the text base. These propositions, even though they may be connected in the text base, are assigned a lower level in it and may be less well retained. Thus, differential recall of theme-relevant propositions may be a result of a reduced level in the text base. The report and the narrative texts may have displayed this possibility.

To summarize, a biasing superordinate context in the form of a title can alter text comprehension in two ways: by guiding the construction of a biased text base, and by rendering sets of propositions unconnected to it. Both ways can explain the differential recall of theme-relevant propositions.

The locus of the biasing effect was assumed throughout this paper to occur at the stage of the text base formation. If a well organized text base was already constructed during reading, then the benefit of a new context at retrieval would be minimal. If, on the other hand, the reader was distracted by, say, counting words (as in Schallert, 1976), a proper text base may never have been constructed during reading, and providing subjects with a superordinate context before retrieval may help them to restructure the propositions which they still remember. A distinction between reading for comprehension vs, reading for other goals may redirect the question of the locus of effect of a superordinate context to task variables. Using biasing contexts and the text's analysis methods that were described in this paper may be useful in resolving some of these issues.

\section{REFERENCE NOTES}

1. Crothers, E. J. Paragraph structure description. Report No. 40, Institute for the Study of Intellectual Behavior, University of Colorado, May 1975.

2. Clark. H. H. Comprehension and the Given-New contract. Paper presented in the conference on "The role of grammar in interdisciplinary linguistic research," University of Bielefeld, Bielefeld, Germany, 1973.
3. Turner, A., \& Greene, E. The construction and use of a propositional text base. Report No. 63, Institute for the Study of Intellectual Behavior, University of Colorado, April 1977.

\section{REFERENCES}

Anderson, R. C., \& Biddle, W. B. On asking people questions about what they are reading. In G. Bower (Ed.), The psychology of learning and motivation (Vol. 9). New York: Acadernic Press, 1975.

Ausubel, D. P. Educational psychology: A cognitive view. New York: Holt, Rinehart, \& Winston, 1968.

Bransford, J. D., \& Johnson, M. K. Contextual prerequisites for understanding: Some investigations of comprehension and recall. Journal of Verbal Learning and Verbal Behavior, 1972, 11, 717-726.

Dooling, D. J., \& LACHMAN, R. Effect of comprehension on retention of prose. Journal of Experimental Psychology, 1971. 88, 216-222.

Dooling, D. J., \& Mullet, R. L. Locus of thematic effect in retention of prose. Joumal of Experimental Psychology, 1973, 97, 404-406.

Fillmore, C. The case for case. In E. Bach \& R. T. Harms (Eds.), Universals in linguistic theory. New York: Holt, Rinehart, \& Winston, 1968.

Frase, L. T. Paragraph organization of written material: The influence of conceptual clustering upon the level and organization of recall. Journal of Educational Psychology, 1969, 60, 394-401.

Frase, L. T. Prose processing. In G. Bower (Ed.), The psychology of learning and motivation ( $\mathrm{Vol}$. 9). New York: Academic Press, 1975.

Frase. L. T.. \& Kreitzberg, V. S. Effect of topical and indirect learning directions on prose recall. Joumal of Educational Psychology, 1975, 67, 320-324.

Frederuksen, C. H. Representing logical and semantic structure of knowledge acquired from discourse. Cognitive Psychology, 1975, 7, 371-458.

GaGNÉ, R. M. Context, isolation and interference effects on the retention of prose. Journal of Educational Psychology, $1969,60,408-414$.

GAGNE, R. M., \& WIEgAND, W. K. The effect of superordinate contexts on learning and retention of facts. Journal of Educational Psychology, 1970, 61, 406-409.

Halliday, M. A., \& Hasan, R. Cohesion in English. London: Longmans, 1976.

Haviland, S. E., \& Clark, H. H. What's new? Acquiring new information as a process in comprehension. Journal of Verbal Learning and Verbal Behavior, 1974, 13, 512-521.

KINTSCH, W. The representation of meaning in memory. Hillsdale, N.J: Lawrence Erlbaum, 1974.

KintsCH, W. On comprehending stories. In P. Carpenter \& M. Just (Eds.), Cognitive processes in comprehension. Hillsdale, N.J: Erlbaum, in press.

Kintsch, W., Kozminsky, E., Streby, W. J., McKoon, G., \& Keenan, J. M. Comprehension and recall of texts as a function of content variables. Journal of Verbal Learning and Verbal Behavior, 1975, 14, 196-214.

MEYER, B. J. F. The organization of prase and its effect on recall. Amsterdam: North Holland, 1975.

SCHALleRT, D. L. Improving memory for prose: The relationship between depth of processing and context. Journal of Verbal Learning and Verbal Behavior, 1976, 15, 621-632.

Thorndyke, $P$. $W$. The role of inference in discourse comprehension. Journal of Verbal Learning and Verbal Behavior. 1976. 15. 437.446.

vaN Disk, T. A. Text and context. London: Longmans, 1976. 
Appendix

Texts Used in the Experiment

\section{Descriptive-Type Text}

It is early in the city, and the sky is slightly milky with the first grays of morning. The ducks in the pond awake, slowly gliding over the glass-like water. Birds awake from all around, their singing breaking up the silence. The sun first appears on the horizon and lights up the haze with a reddish glow. The church bell lets out its first clang of the morning. The rumble of local buses and delivery trucks produces a low hum throughout the city. The rhythmic clatter of wooden shoes on the cobblestone lane livens the early morning pace. The blue sky of day gradually replaces the morning's fiery red. The women gather in the market chattering and cackling in high-pitched emotional tones. Their small children, hungry and bored, wailed loudly for their mothers' attention. It gets very bright as the sun rises high in the sky. At the schools policemen signal for cars to stop, allowing youngsters going home for lunch to cross at the intersections. The boys make a lot of noise in the process. Coming back later on, they are more subdued. As the hot afternoon wears on, people everywhere stop to quench their thirst at their favorite gin mills. Some stagger out hours later from the dark barrooms, weaving their way through the narrow streets. It cools down as the weather clouds up. Sirens fill the air as an ambulance whizzes by, bound. for the hospital. The church bell sounds again, ominously. The light becomes dim as the sun begins to set. The policemen again direct traffic during the rush hour, their dark uniforms fading into the evening. Exhausted workers are heard trudging homeward. The quietness of the country descends over the city with the night, broken up mainly by roaming transistor radios. A full moon is seen in the dark sky, lighting up the slowly moving clouds all around it.

\section{Report-Type Text}

Back in the days when Archie McGillis was the owner and skipper of the Malahat, she was not only the pride of the liquor fleet but a genuine thorn in the side of the United States Coast Guard. Acting as a mother ship, she made about two trips per year stacking to the gunwhales with whiskey. Though the movements of the Malahat were not publicized, the underworld had a secret network of information that eluded the everwatchful eye of the law. In the dark of the night, mosquito boats came out to the fringe of the 3-mile limit to meet her and load up. Liquor shipments were taken out of wooden cases and sewed into burlap sacks, a dozen bottles to the parcel. It was more easily handled this way in small shiploads and also economized on space. Furthermore, it was discarded much more easily should the rumrunners fall under the probing searchlight of the government vessels.

The Coast Guard tried various ways to stop the illicit trade. Their strategy was two-fold: First of all, they tried to catch the vessel inside the 3-mile territorial limit. The Coast Guard could then legally seize the ship and its cargo. Once, FBI agents were employed, pretending to be customers. They tried to trick the ship's captain into meeting their boats closer to the coast, in $U$.S. waters. When this plan failed, the second line of defense was to intercept the loaded mosquito boats returning to the California coast. They succeeded in doing this many times. Not much liquor was confiscated this way, however, since the boats held a limited capacity, but the captured bootleggers often became a source of valuable information.

\section{Narrative-Type Text}

My name is Debbie. As a student nurse, one of my assignments was at a mental hospital. I was so unsure of myself that on the day I was to meet my assigned patient, I reviewed her case history twice. Betty was an obese, 67-year-old chronic schizophrenic. At $4 \mathrm{ft} 10 \mathrm{in}$. and $225 \mathrm{lb}$, she was on a reducing diet. I noted with surprise that, so far, she'd gained $5 \mathrm{lb}$ on the diet. The first few times I met Betty I was being friendly, but she greeted me with hostility and contempt. I was so anxious about this hostility that I couldn't write a good care plan for my course. Then I decided I'd attack the obvious problem-Betty's obesity. Betty's husband used to run around with pretty women, especially skinny ones. When he was out with them, she would stay home and eat. She became a compulsive eater this way. She became so obese that walking was a chore. Still, I wondered how she was gaining on a diet. I observed her at meal times. Sure enough, Betty was eating off other patients' trays. When I sat with her during a meal, however, I ended this behavior. I also planned an exercise program for her. At first, she was most resistant to this change. I made it a point to exercise with her. Later, she would exercise without coaxing. I found simple tasks for her to do. She agreed to help clean up the day-room, and she was keeping it neat. My plan was so effective that I earned a grade of " $A$ " on that course. Betty slowly began to lose weight, but most importantly, she found a way to channel her energy nondestructively. Her compulsivity took the form of cleaning up all the time.

(Received for publication January 6, 1977; revision accepted May 12,1977.) 